\title{
Motivational Context and Perfectionism Traits in Pediatric Sports
}

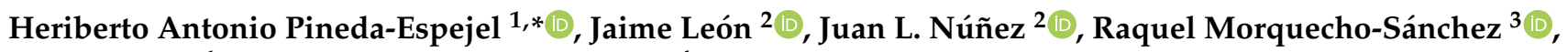 \\ Marina Trejo ${ }^{1}$ and Verónica Morales-Sánchez ${ }^{4}$ \\ 1 Facultad de Deportes, Universidad Autónoma de Baja California, Mexicali 21100, Mexico; \\ marina.trejo@uabc.edu.mx \\ 2 Departamento de Psicología, Sociología y Trabajo Social, Universidad de Las Palmas de Gran Canaria, \\ 35001 Las Palmas de Gran Canaria, Spain; Jaime.leon@ulpgc.es (J.L.); Juanluis.nunez@ulpgc.es (J.L.N.) \\ 3 Facultad de Organización Deportiva, Universidad Autónoma de Nuevo León, \\ San Nicolás de los Garza 66451, Mexico; raquel.morquechosn@uanl.edu.mx \\ 4 Departamento de Psicología Social, Universidad de Málaga, 29071 Málaga, Spain; vomorales@uma.es \\ * Correspondence: Antonio.pineda@uabc.edu.mx
}

check for updates

Citation: Pineda-Espejel, H.A.; León, J.; Núñez, J.L.; Morquecho-Sánchez, R.; Trejo, M.; Morales-Sánchez, V. Motivational Context and Perfectionism Traits in Pediatric Sports. Sustainability 2021, 13, 11639. https://doi.org/10.3390/ su132111639

Academic Editors: Carlos Salavera and Marc A. Rosen

Received: 22 May 2021

Accepted: 29 September 2021

Published: 21 October 2021

Publisher's Note: MDPI stays neutral with regard to jurisdictional claims in published maps and institutional affiliations.

Copyright: (c) 2021 by the authors. Licensee MDPI, Basel, Switzerland. This article is an open access article distributed under the terms and conditions of the Creative Commons Attribution (CC BY) license (https:// creativecommons.org/licenses/by/ $4.0 /)$.

\begin{abstract}
In sports, one of the social agents who can pressure an athlete for perfection in their performance is their coach. However, perfectionism has many potential negative consequences such as excessive concerns over even minor mistakes. The purpose of this study is to test a sequential model: the motivational context (i.e., task- and ego-involving climates generated by the coach and a coach's support for autonomy) and the facets that determine the level of perfectionism exhibited as a trait (i.e., perceived coach pressure - a facet of socially prescribed perfectionism-and concerns over mistakes-a facet of self-oriented perfectionism). The sample included 317 athletes (133 boys and 184 girls) aged between 10 and 14 years, who answered a battery of questionnaires that evaluated an athlete's perception of their motivational climate, their perception of support for autonomy, their perceived coach pressure and their concerns over mistakes. Using the structural equations model, the results showed that the task-involving climate was negatively correlated with perceived coach pressure, whereas the ego-involving climate and support for autonomy were positively correlated with perceived coach pressure and were positively correlated with concerns over mistakes. Finally, perceived coach pressure did not influence concerns over mistakes from the motivational context. This study highlights the importance of considering motivational contexts as important motivational elements of perfectionism in youth sports.
\end{abstract}

Keywords: motivation; personality; dispositional dimensions; young athletes; psychosocial perspective

\section{Introduction}

Motivation is defined as the process by which activities are started, directed and sustained. Within the sports context, coaches play an important role in the development of athletes' experiences by interacting with them on a regular basis and by using a variety of strategies to achieve certain results [1]. For example, some studies show that behaviors from coaches are associated with perceptions of competence [2], burnout [3], or motivational regulations in youth sports $[3,4]$.

Two motivational theories that study the influence of an athlete's social environment are achievement goals theory (AGT) [5] and the self-determination theory (SDT) [6]. These two theories are neither in opposition to one another nor disjunctive; rather, they complement each other [7]. On the one hand, AGT affirms that people are intentionally goal-directed organisms and that they act in accordance with their goals. This theory considers the contextual perspective through motivational climates, known as the environment constituted by implicit and explicit signals exhibited by significant others, which establishes patterns of success [5]. Two types of motivational climates can be distinguished: 
a task-involving climate and an ego-involving climate. In the first one, participants perceive that significant others place a situational focus on self-improvement, learning and mastering through emphasis on effort and progress. In the second one, ego-involving climate, their perception of situational focus is on normative criteria (e.g., a comparison of personal results and abilities with those of others), on competition and on rejection of mistakes.

On the other hand, SDT $[8,9]$ is an empirically derived theory of human motivation and personality in social contexts that details the origins and outcomes of human agentic action. SDT also describes perceived supportive interpersonal behaviors and frustrating interpersonal behaviors [10]. For example, included within supportive interpersonal behaviors is support for autonomy, where behaviors offer options and allow for initiative, choice and decision making. Moreover, it promotes a commitment to tasks, recognizes negative feelings [11,12] and provides appropriate expectations in the learning process [13].

The sports context is characterized by the importance it places on competition, social comparison, winning and public recognition of the skills shown [5] as well as by the harshness of training sessions and harsh criticism in competition, characteristics associated with perfectionism [14]. Therefore, there are logical and conceptual arguments to associate motivational context with perfectionism; for example, in an environment where mistakes are accepted as part of the learning and performance process, it would lead to the development of lower levels of perfectionism.

Perfectionism involves expressions and thoughts about perfection [15] and is a multilevel, multidimensional and multifaceted personality style. Thus, it can operate at several behavioral levels. For example, it can function at a trait level, with dimensions representing dispositional factors that reflect self-perfectionism etc. $[15,16]$. At the level of traits, two dispositional dimensions can be identified: self-oriented perfectionism, which involves personally requiring absolute perfection [16] and socially prescribed perfectionism, which involves the belief that others demand or expect perfection [15].

Self-oriented perfectionism reflects, for example, a tendency to focus on performance failures or defects [17]. These aspects can be associated with facets such as concerns over mistakes, which reveals negative reactions to mistakes, a tendency to interpret mistakes as equivalent to failure and a tendency to believe that one could lose respect from others following failure [18]. Meanwhile, socially prescribed perfectionism refers to the perception that others have excessive perfectionist standards about them and that they may be disapproved of by others if those standards are not achieved [16]. That is, these individuals typically perceive the presence of powerful external demands for perfection from others. This dimension is associated with the perception of negative evaluation from others [19-21] or perceived parental pressure for perfection [22].

Within the sports context, the coach is considered very influential [23] and, therefore, is included as the construct perceived coach pressure, which involves a pressure to be perfect according to the expectations of the athlete's models or a standard of sports performance, which are perceived to be externally enforced by the coach, whom the athlete seeks to please or at least not to disappoint.

Perfectionism is a construct inherently associated with motivation [16]. The motivational climate and perfectionism are considered central elements of a motivational effort and achievement pattern [24]. Thus, some studies have correlated motivational climate and perfectionism traits. For example, outside the sports context, it has been observed that children with parents who emphasized performance goals, something typical of an ego-involving climate, exhibited "dysfunctional perfectionism" (a construct involving a combination of concerns about mistakes, doubts about actions, parental expectations and parental criticism), compared with those who perceived that their parents emphasized learning goals, something typical of a task-involving climate [25]. Furthermore, a taskinvolving climate generated by a teacher is negatively related to concerns over mistakes in physical education [26]. 
In teenagers and adult dancers, a task-involving climate was negatively related to concern over mistakes and parental expectations, but not to parental criticism (both characteristics of perceived parental pressure). Therefore, ego-involving climate generated by a teacher was positively related to concern over mistakes and parental criticism and expectations, while concern over mistakes was positively related to the criticism and expectations of parents [27]. On another study with dancers, the concern over mistakes positively influences perceptions of ego-involving climate and negatively impacts the perceptions of task-involving climate over time [28].

In the sport context, perfectionism (integrated by concern over mistakes, doubts about actions, parental criticism and expectations) were positively related to ego-involving climate and negatively with task-involving climate, although in the latter case with a low coefficient $[2,29]$. In a sample of high-performing youth and Olympic athletes, taskinvolving climate was negatively related to concern over mistakes and ego-involving climate related positively [30].

On the other side, the coach's criticism (a component of perceived coach pressure) was related to both the ego-involving climate and concern over mistakes. The last, likewise, was related to the ego-involving climate, both in male football players [31] and Olympic athletes [32]. A longitudinal study with young athletes showed that the coach pressure is associated with perfectionistic concerns in a general way and both at time 1 and three months later [33].

Regarding perceived interpersonal behaviors, only one study with a sample of adult swimmers proves that controlling style predicts socially prescribed perfectionism [3]. Previous evidence indicates that the role of motivational context plays in the development perfectionism traits has received little attention in the pediatric sport context. In addition, the majority of these studies have focused on perceived parents' pressure, for example [34], in sport context, one of the social agents who can pressure for perfection is the coach. Only one study analyzed the perceived coach pressure in youth sport [31]. Furthermore, no study has analyzed the impact of autonomy support.

To our knowledge, no study has integrated the AGT and SDT with perfectionism development theory to improve understanding of the nature of the multivariate relationship between motivational context and perfectionism traits in pediatric sports. We understand that the use of different theories in the same study is necessary and enriching.

Following approximations from previous studies that have jointly analyzed the motivational climate and autonomy support, for example [7,35], and whereas the perceived coach pressure can culminate in negative consequences, such as concern over mistakes, or concern about not reaching high-performance standards [21]; this study aims to test the sequential model: motivational context (i.e., task and ego-involving climates generated by the coach and coach's autonomy support), aspects of perfectionism traits (i.e., perceived coach pressure-a facet of dimension socially prescribed perfectionism and concern over mistakes - a facet of dimension self-oriented perfectionism).

The following hypotheses were tested:

Hypotheses 1 (H1). Motivational context, determined by the task-involving climate, ego-involving climate and autonomy support, will have effects on the perceived coach pressure.

Hypotheses 2 (H2). Perceived coach pressure will be positively associated with concern over mistakes.

Hypotheses 3 (H3). Perceived coach pressure will have a mediating effect on the relationship between motivational context and concern over mistakes (See Figure 1). 


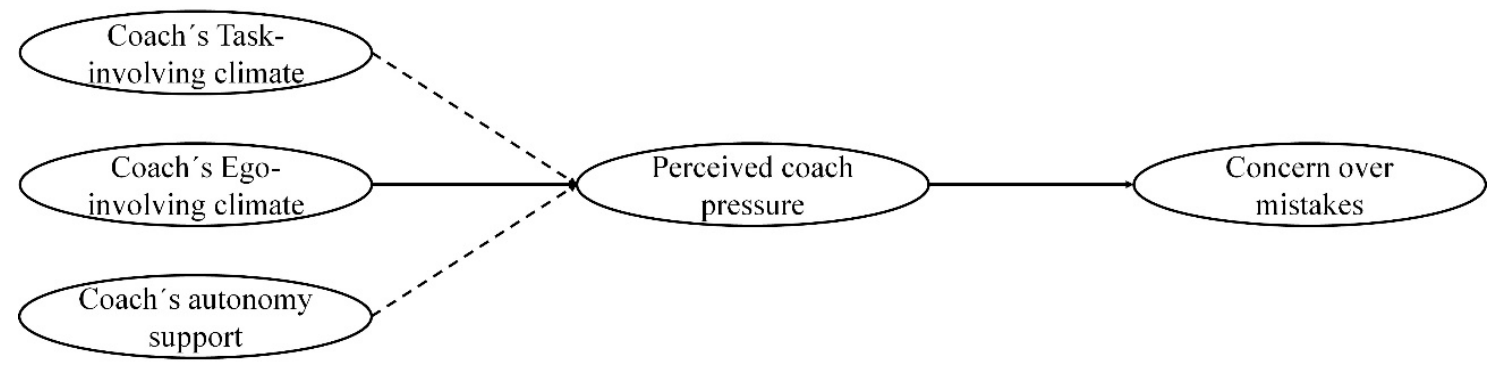

Figure 1. Hypothesized structural model. The continuous arrows indicate a positive relationship and the dashed arrows represent a negative relationship.

\section{Method}

This study is an empirical work, a quantitative methodology with a cross-sectional design and a non-probability sampling for convenience, most commonly used in sports context.

\subsection{Participants}

The participants were 377 athletes (163 boys and 214 girls) from Baja California State, Mexico. The age range of the participants was from 10 to 14 years $(M=12.58, S D=1.70)$. Participants of recreational level practiced cooperation-opposition (e.g., baseball, basketball, soccer and volleyball) and individual (e.g., athletics, gymnastics, swimming and weightlifting) sports. The mean of sports experience was 3.66 years $(S D=2.81)$ and a mean of $2.41 \mathrm{~h}$ of daily training $(S D=0.80)$.

\subsection{Instruments}

\subsubsection{Sociodemographic and Sports Data}

To describe the sample, the participants indicated their age, sex, level of competition, practice history and federation to which they belonged.

\subsubsection{Motivational Climate}

In order to measure the motivational climate generated by the coach, the Spanish version of the Perceived Motivational Climate in Sport Questionnaire, adapted to the Mexican context, was used (PMCSQ-2) [4]. It consists of 24 items that precede the initial phrase "In my training group ..." and are connected in two first-order factors (taskinvolving climate and ego-involving climate). Each one consists of some second-order subscales (task-involving climate: cooperative learning (e.g., "Athletes help each other to learn"), effort and improvement (e.g., "Effort is rewarded"); ego-involving climate: intragroup conflict (e.g., "Athletes are encouraged to compete with each other"), uneven recognition (e.g., "The coach has his favorite athletes"), punishment for mistakes (e.g., "Athletes are afraid of failing")). These items are answered using a 5-point Likert scale ranging from 1 (never) to 5 (always).

\subsubsection{Coach's Autonomy Support}

To measure the interpersonal style of autonomy support generated by the coach, the reduced version of the adaptation in Spanish of the Sports Climate Questionnaire (S-SCQ) [36] was applied. It is composing of six items (e.g., "In my sport I feel understood by my coach"). Responses are collected on a 7-point Likert scale ranging from 1 (not true) to 7 (very true).

\subsubsection{Perceived Coach Pressure}

To measure the perceived pressure to be perfect coming from the coach, the "perceived coach pressure" subscale of the Multidimensional Inventory or Perfectionism in Sport adapted to Spanish version was used (MIPS) [37]. It consists of eight items (e.g., "My 
coach expects my performance to be perfect") which are answered on a 6-point Likert scale ranging from 1 (never) and 6 (always).

\subsubsection{Concern over Mistakes}

In order to measure the concern over mistakes in sports, "concern over mistakes" subscale of the adaptation to Spanish of the Sport Multidimensional Perfectionism Scale-2 was used (Sport-MPS-2) [38]. Modifications to the phrases were made to increase item clarity for the target age group. It consists of seven items (e.g., "If I fail in a competition, I feel like a failure as a person") which are answered with a 5-point Likert scale that ranges from 1 (totally disagree) to 5 (totally agree).

\section{Procedure}

All subjects gave their informed consent before they participated in the study. The study was conducted in accordance with the Declaration of Helsinki and the protocol was approved by the Ethics Committee of Universidad Autónoma de Baja California (Project 1149). The data collection was conducted at different municipal sports clubs and facilities. Coaches were contacted and informed about the objectives of the study, as well as asked for permission for the athletes to participate. In line with APA ethical principles, the study was briefly described to athletes and their parents. The latter gave their informed consent before they participated in the study. A pilot test of the application of instruments was conducted out with child-aged subjects to ensure comprehension of the items. Afterwards, in the data collection, the researcher explained the questionnaire battery and was present to answer questions. A member of the research team was always available to maintain the rigor of the correct application of the instrument. Measurements were taken before or after a regular training session. It was emphasized that there were no right or wrong answers and that the answers were voluntary and anonymous. The questionnaires were completed in 15 min approximately.

\section{Data Analysis}

The reliability of the instruments was reviewed through McDonals's omega coefficient for the analysis of internal consistency, where acceptable values are from 0.70 to 0.95 [39]. All data were expressed as mean and standard deviation. Pearson's correlation coefficient was used to determine the correlation between the study variables. These analyzes were performed with the SPSS 23 program. Statistical significance was $p<0.05$.

With the MPlus 7.0 program [40], a confirmatory factor analysis (CFA) was performed for the measurement model. In addition, structural equation model (SEM) was executed to test the hypothesized structural model, where motivational climates and the autonomy support predict concern over mistakes through perceived coach pressure. These analyses were based on the robust maximum likelihood (MLR) estimator. This estimation provides standard errors and fit indices that are robust to the Likert nature of the items and possible normality violations. Given the sample size, this was carried out with items with factorial loadings greater than 0.50 in the CFA, according to the suggestion by Hair, Babin, Anderson and Black [41]. A command type = complex was included to control the fact that athletes are nested under coaches.

The model fit was evaluated using the $\chi^{2} / d f$ ratio $\leq 2$ (good model fit) [42]. In addition to applying the root mean square error of approximation (RMSEA) with its $90 \%$ confidence interval, comparative fit index (CFI) and Tucker-Lewis index (TLI). Values of less than 0.06 indicate a good fit of the model for the RMSEA [42,43], while values greater than 0.95 indicate an excellent fit for CFI and TLI [42].

To test the proposed interactions, a parallel mediation analysis according to Preacher and Hayes [44], namely, model 4, recommendations were conducted using PROCESS for SPSS. This procedure allows the estimation of the direct and indirect effects in the proposed model. In the independent-dependent variables interaction, bias-correct bootstrapped point estimates were calculated (considering standard errors and 95\% IC). Bootstrap with 
5000 samples were used, since it is recommended with rather small samples, significant indirect effects were considered when zero is not contained within the confidence interval [45]. The estimation for the confidence intervals was performed using the ordinary least squares (OLS) and maximum likelihood (ML) methods. Additionally, the total effects of the mediation model were calculated.

\section{Results}

\subsection{Preliminary Analysis}

Table 1 presents the mean and standard deviation for each variable. Based on the nominal midpoint of the response scales, all participants presented a high perception of task-involving climate and the coach's autonomy support, as well as moderate perceived coach pressure, low concern over mistakes and ego-involving climate. On the other hand, the ego-involving climate correlated positively and significantly $(p<0.01)$ with the perceived coach pressure and concern over mistakes. These last two variables correlated positively with each other.

Table 1. Descriptive statistics and correlation matrix.

\begin{tabular}{cccccccc}
\hline & Range & $\boldsymbol{M}$ & SD & $\mathbf{1}$ & $\mathbf{2}$ & $\mathbf{3}$ \\
\hline 1 Task-involving climate & $1-5$ & 3.80 & 0.69 & & & & \\
2 Ego-involving climate & $1-5$ & 2.46 & 0.72 & -0.14 & & \\
3 Autonomy support & $1-7$ & 5.33 & 1.39 & $0.28^{* *}$ & $-0.29^{* *}$ & 0.13 & \\
4 Perceived coach pressure & $1-6$ & 3.28 & 0.99 & -0.13 & $0.53^{* *}$ & $-0.17^{*}$ & $0.28^{* *}$ \\
5 Concern over mistakes & $1-5$ & 2.06 & 0.76 & -0.15 & $0.35^{* *}$ & \\
\hline
\end{tabular}

Note: ${ }^{* *} p<0.01 ; * p<0.05$

\subsection{Confirmatory Factor Analysis}

The CFAs confirmed the structure of the instruments and determined that the observed variables were indeed good indicators of the latent variables. The measurement model of each scale in the current study provided adequate fit and the factor loadings were above 0.39 . The corresponding reliability was adequate: above 0.71 (Table 2).

\subsection{Path Analysis}

The path analysis model provided an excellent fit for the data: $\chi^{2} / d f=1.49, p>0.05$; RMSEA $=0.05(90 \%$ CI $[0.01,0.15]) ; C F I=0.98 ; \mathrm{TLI}=0.95$. Significant path coefficients (standardized estimated) of model are presented in Figure 2, where task-involving climate was associated negatively with the perceived coach pressure with $\beta=-0.15(95 \% \mathrm{CI}$ $[-0.26,-0.03] ; p=0.03]$; while ego-involving climate and coach's autonomy support were associated positively with the perceived coach pressure with $\beta=0.61$ (95\% CI [0.53, 0.70]; $p<0.001$ ) and $\beta=0.34$ (95\% CI [0.23, 0.46]; $p<0.001)$, respectively; and then perceived coach pressure was associated positively with concern over mistakes with $\beta=0.36(95 \%$ CI $[0.21,0.51] ; p<0.001)$. The variance percentage explained by the model was $39 \%$ for perceived coach pressure and $13 \%$ for concern over mistakes.

\subsection{Simple Mediation}

From the SEM results, three serial mediation effects were tested. Figure 3 presents the results of the perceived coach pressure mediating effects on the relationship between each of the motivational context (i.e., task-involving climate, ego-involving climate, autonomy support) and the concern over mistakes outcome.

The indirect effect was not statistically significant in the mediations tested because the confidence interval includes the value zero (Table 3), for this reason the perception of pressure does not condition the concern over mistakes. In other words, the indirect effects are not explained by the mediating variable. Thus, both ego-involving climate (Figure 3B) and autonomy support (Figure 3C) were directly and significantly related to concern about errors, the first one positively and the second one negatively. Contrary task-involving 
climate did not show significant effects on perceived coach pressure neither concern over mistakes (Figure 3A).

Table 2. Fit indices, reliability and factor loadings by the measuring instruments.

\begin{tabular}{|c|c|c|c|c|c|c|}
\hline Instrument & $\chi^{2} / d f$ & Sig. & RMSEA $(90 \% \mathrm{CI})$ & CFI & TLI & $\omega$ \\
\hline PMCSQ-2 & 5.02 & $p<0.001$ & $0.08(0.07,0.09)$ & 0.90 & 0.88 & $\begin{array}{l}0.79 \mathrm{TC} \\
0.81 \mathrm{EC}\end{array}$ \\
\hline S-SCQ & 5.12 & $p<0.001$ & $0.07(0.03,0.12)$ & 0.96 & 0.94 & 0.89 \\
\hline MIPS (Perceived Coach Pressure) & 5.00 & $p<0.001$ & $0.07(0.04,0.11)$ & 0.90 & 0.86 & 0.79 \\
\hline Sport-MPS-2 (Concern over Mistakes) & 5.01 & $p<0.001$ & $0.07(0.04,0.98)$ & 0.91 & 0.86 & 0.71 \\
\hline Item & $\lambda$ & $\sigma$ & Item & $\lambda$ & $\sigma$ & \\
\hline TC1 & 0.75 & 0.04 & S-SCQ1 & 0.84 & 0.03 & \\
\hline TC2 & 0.77 & 0.04 & S-SCQ2 & 0.90 & 0.02 & \\
\hline TC3 & 0.67 & 0.05 & S-SCQ3 & 0.78 & 0.03 & \\
\hline TC4 & 0.45 & 0.06 & S-SCQ4 & 0.81 & 0.03 & \\
\hline TC5 & 0.30 & 0.07 & S-SCQ5 & 0.78 & 0.03 & \\
\hline TC6 & 0.59 & 0.06 & S-SCQ6 & 0.77 & 0.03 & \\
\hline TC7 & 0.24 & 0.07 & MIPS1 & 0.43 & 0.06 & \\
\hline TC8 & 0.60 & 0.05 & MIPS2 & 0.74 & 0.04 & \\
\hline TC9 & 0.71 & 0.05 & MIPS3 & 0.68 & 0.04 & \\
\hline TC10 & 0.69 & 0.05 & MIPS4 & 0.70 & 0.04 & \\
\hline TC11 & 0.57 & 0.06 & MIPS5 & 0.73 & 0.04 & \\
\hline EC1 & 0.51 & 0.06 & MIPS6 & 0.51 & 0.06 & \\
\hline EC2 & 0.72 & 0.04 & MIPS7 & 0.40 & 0.06 & \\
\hline EC3 & 0.78 & 0.04 & MIPS8 & 0.62 & 0.05 & \\
\hline EC4 & 0.39 & 0.09 & Sport-MPS-21 & 0.39 & 0.07 & \\
\hline EC5 & 0.59 & 0.06 & Sport-MPS-22 & 0.44 & 0.07 & \\
\hline EC6 & 0.58 & 0.06 & Sport-MPS-23 & 0.56 & 0.06 & \\
\hline EC7 & 0.60 & 0.06 & Sport-MPS-24 & 0.74 & 0.05 & \\
\hline EC8 & 0.52 & 0.07 & Sport-MPS-25 & 0.64 & 0.05 & \\
\hline EC9 & 0.83 & 0.03 & Sport-MPS-26 & 0.52 & 0.06 & \\
\hline EC10 & 0.39 & 0.08 & Sport-MPS-27 & 0.76 & 0.05 & \\
\hline EC11 & 0.69 & 0.05 & & & & \\
\hline EC12 & 0.39 & 0.07 & & & & \\
\hline EC13 & 0.72 & 0.05 & & & & \\
\hline
\end{tabular}

Note: TC = Task-involving climate; EC = Ego-involving climate; $\omega=$ composite reliability; $\lambda=$ factor loading; $\sigma=$ standard error; Sig. $=$ significance. All factorial weights were significant at the $p<0.001$ level.

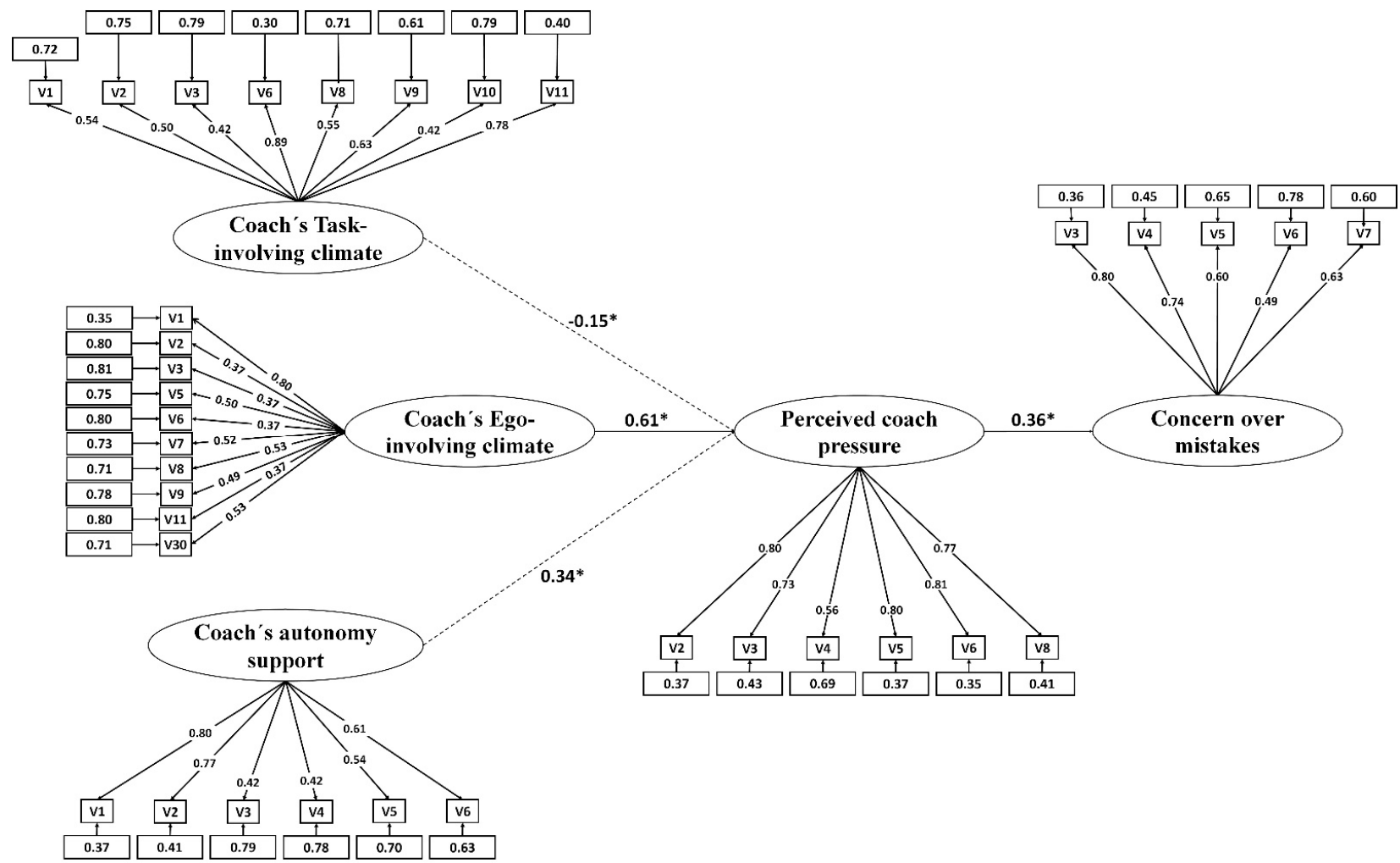

Figure 2. Standardized solution of the structural model. ${ }^{*} p<0.05$. 


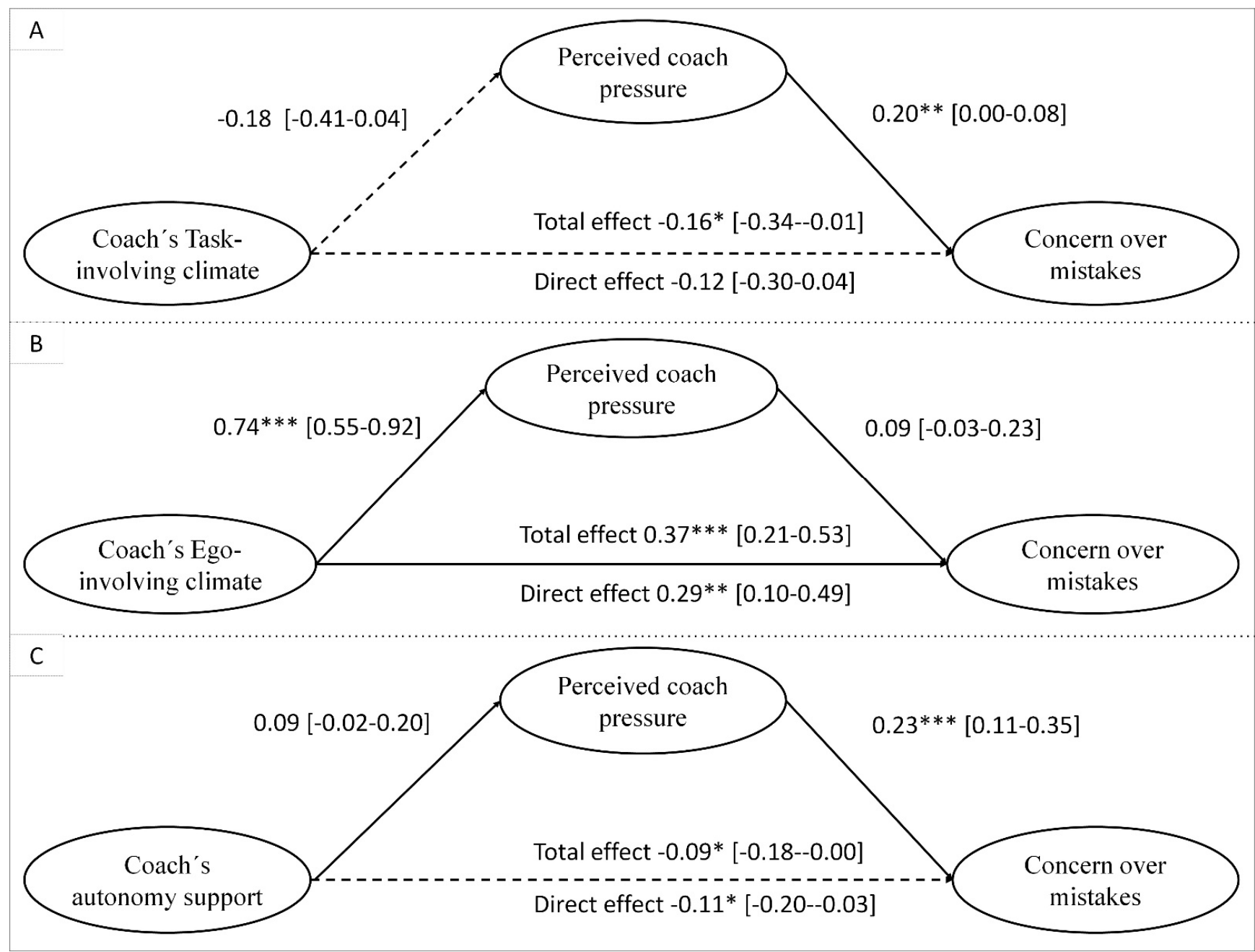

Figure 3. Serial mediation models. $95 \% \mathrm{CI}$ estimate indicate a significant indirect effect. Non-standardized coefficients are shown. (A-C) refers to each of the serial mediation models tested. ${ }^{*} p<0.05,{ }^{* *} p<0.01,{ }^{* * *} p<0.001$.

Table 3. Superior combined indirect effects after contrast of mediators in tested sequences.

\begin{tabular}{cc}
\hline Sequences & Indirect Effect (95\% CI) \\
\hline $\begin{array}{c}\text { Task-involving climate-perceived coach } \\
\text { pressure-concern over mistakes }\end{array}$ & $-0.03(-0.10$ to 0.01$)$ \\
$\begin{array}{c}\text { Ego-involving climate-perceived coach } \\
\text { pressure-concern over mistakes }\end{array}$ & $-0.07(-0.04$ to 0.19$)$ \\
$\begin{array}{c}\text { Autonomy support-perceived coach } \\
\text { pressure-concern over mistakes }\end{array}$ & $-0.02(-0.00$ to 0.05$)$ \\
\hline
\end{tabular}

\section{Discussion}

The perceived interpersonal behaviors of the coach and the motivational climate that these can generate in training are essential contextual elements that can explain a wide variety of the athletes' behaviors. Moreover, few studies have analyzed the role that these motivational context plays in the development of dispositional dimensions of perfectionism. In order to increase the understanding of the multivariate nature between the motivational context and facets of perfectionism traits dimension in sport, this study was performed.

The results partially confirm the first hypotheses proposed, in which the motivational context, determined by the task-involving climate, ego-involving climate and autonomy support, has effects on perceived coach pressure. First, task-involving climate has a negative effect on perceived coach pressure. This result is consistent with the postulates of the AGT. 
In a task-involving climate, approval and affection are provided unconditionally, regardless of performance standards, since it emphasizes performing a task in the best possible manner under self-referential success criteria [5] and not under normative criteria. Thus, the young athletes can perceive that their coach does not impose high performance standards, or criticize their performance when this is not excellent, nor he/she is disappointed with athletes when their performance is not perfect. Such a result coincides with previous study approaches both outside [27] and within the sports context, where the figure of the parents was considered, and not the coach's figure [2,29]. Furthermore, the negative effect of the task-involving climate on perceived coach pressure can be explained, because task-involving climate individuals are encouraged to learn from mistakes and persist despite difficulties. These signs promote athletes to not perceive that their coach sets high-performance standards and that is very critical about its performance. Moreover, the athletes tend to develop low levels of concern over mistakes (a facet of self-oriented perfectionism). In this way, there will be more optimal functioning in the developed task.

Second, the results indicate that ego-involving climate has a positive effect on perceived coach pressure. In this climate, the focus is on normative criteria since the coach compares the performance of the athlete with a specific standard that should be achieved, focusing more on mistakes [46]. Given that in an ego-involving climate, success consists of demonstrating impeccably or unsurpassed in accuracy greater ability than others and doing better than others [47], so athletes can perceive that their coach imposes high-performance expectations on them, that the coach criticizes publicly or privately in their execution when it is not excellent and is not satisfied with their performance. Previous mentioned result lays within the same line of previous studies, both outside [25-27] and within the sports context, where parents $[2,29]$ or coaches $[31,32]$ were considered as a source of pressure.

Third, the results reject one of the hypothesized effects and show a positive effect between the coach's autonomy support and perceived coach pressure. It is necessary to clarify that perceived coach pressure does not imply punishing behaviors, nor conditional love. In this case, the athletes can perceive that their coach provides reasons and explanations for adopting certain behaviors and perfect actions in sport, with the intention of directing their efforts towards a certain goal. The coach can offer their athletes choices in training and can even develop empathetic behaviors towards the negative emotions. Additionally, at the same time, athletes can perceive that their coach demands certain expectations and levels of performance that can make the athletes feel overwhelmed to achieve these expectations. It should be noted that this perception or belief may or may not be veridical [15].

An explanation of the above can be supported by Baumrind [48]. He pointed out that within the family context and extrapolated to the sports context, perfectionist coaches are very demanding, but much less controlling and more receptive, since they support the needs of their athletes and facilitate their perception so that they can overcome the challenges of an activity.

The positive association between a coach's autonomy support and perceived coach pressure is an innovative finding in the SDT literature. There can be various reasons why a coach who supports the autonomy of their athletes may pressure them to be perfect. Thus, coaches can feel pressure from their superiors, bosses or employers to obtain certain results [49]; they can feel compelled to reached a result imposed by their authorities or colleagues [50], either to obtain an award for that result or evaluation based on results [51,52]. All of this can be associated with conflict, job insecurity or few opportunities for career growth [53]. Consequently, they pressure for perfection since they believe this is essential in sports. Otherwise, they are unlikely to meet the performance expectations of superiors, colleagues or parents of athletes. When external pressure is experienced, the person in authority can press for perfection [54], without necessarily adopting a controlling style as a motivating strategy. Instead, they want their athletes to reach the standard to which they are being evaluated [55]. 
The second hypothesis is confirmed, since the athletes who perceived that the coach exerts onto them, to achieve performance perfection, have negative reactions to mistakes and a tendency to interpret mistakes as equivalent to failure, that would be accompanied by the disapproval of the coach [56]. This confirms that perceived coach pressure is related to concern over mistakes [57] and is consistent with other studies, for example [21,27]. This can have negative consequences on the quality of their performance, which will tend to make athletes strive toward their goals out of fear of failure, avoid rejection, rather than out of the need for achievement. Because imperfection portends something undesirable, athletes strive to meet the excessively high standards of coaches for approval and to avoid criticism.

The third hypothesis is not confirmed, since perceived coach pressure does not condition the concern over mistakes from motivational contexts. So, if the coach creates an ego-involving climate, then, in a direct way, it means that young athletes worry about making mistakes in training or competitions. Consequently, sports performance may be affected, since studies show that athletes who have concern over mistakes make less effort in sports tasks [58] and have less concentration [59]. The opposite is done if the coach generates primarily a task-involving climate or an autonomy support style.

\subsection{Implications}

From a theoretical point of view, this study contributes to the literature that motivational contexts help to improve the understanding of perfectionism traits in sports for children and adolescents. The abovementioned was achieved by forming a link between different motivational theories. This research supports the idea that the motivational context is an influential environmental factor on the perfectionism traits dimension. So, in a way, perfectionism develops in response to social practices.

From a practical point of view, this study is important, since athletes and coaches can better understand the social environments that promote perfectionism traits' dimensions in athletes. In addition, later, they can promote more adaptive practices that may reduce negative experiences of athletes in their training. In addition, it also helps to generate useful empirical information that can be applied by sports psychologists while approaching perfectionism traits. The results suggest the importance of generating a task-involving climate in training, because that helps the athlete focus on personal improvement, learning and mastery, emphasizing effort and implication and, at the same time, to enable them to develop low or weak evaluative concerns of achieving standards performance [21].

This study addressed the psychosocial factors of identifying performance elements, specifically how the behaviors, strategies and beliefs of coaches influence the concern over mistakes. Such knowledge provides major compression for coaches when ensuring the sustainability of the long-term management model in facilitating stimulating training environments and create a better psychological sport experience for pediatric athletes. Therefore, the data in this study are relevant for athletes, trainers and even sports institutions.

\subsection{Limitations and Future Perspectives}

The present study provides important scientific evidence on the prediction between the motivational context generated by a coach and perfectionism traits in child and adolescent athletes; however, it also has limitations. Intentional sampling does not allow the results to be generalized, although it does concede testing the correlation between variables that the literature assumes to be homogeneous across populations. Additionally, due to a crosssectional design being performed, it is not possible to examine the correlation between the variables studied over time, since relatively stable variables may present certain variations in the time that alter the conclusions. For that reason, causality cannot be assessed.

The results may have been influenced by the age of the participants and the understanding of the items. All measures were self-reports; therefore, there could be ambiguity in the perceptions of environmental stimuli. So, the study may benefit from the combination of both self-reports and the reports that were given by other informants, or a study with 
coaches and not with athletes could have been made. Another limitation is the lack of research background regarding the hypothetical model proposed, which makes it difficult to contrast with the results of other studies within the same context. The reason for which more studies would be desirable is so that the empirical evidence can support or refute the current findings from different samples, sports and contexts. In other future lines of research, it is suggested to include others supportive interpersonal behaviors and thwarting interpersonal behaviors variables, as well as to include other facets of the perfectionism traits' dimensions.

\section{Conclusions}

Despite its limitations, this study is useful and innovative because it establishes that a task-involving climate is negatively associated with perceived coach pressure, while an ego-involving climate and autonomy support do so positively. Perceived coach pressure is positively associated with concern about mistakes. In addition, the concern for errors in sports actions during childhood and adolescence is directly influenced by different environments generated by external social agents, such as the coach. Specifically, therefore, the environments generated by the coach should be taken into consideration, since they improve the psychological functioning of athletes and can help to plan intervention programs to improve the adaptive behaviors of athletes.

What Does This Article Add?

This study is carried out by relating AGT and SDT with perfectionism development theory to improve understanding of the nature of the multivariate relationship between motivational context and the perfectionism traits' dimensions. Therefore, this study tests a model that analyzes the motivational context and dispositional dimensions of perfectionism traits level in youth sports, through the sequence: motivational context-perceived coach pressure-concern over mistakes. They include variables such as autonomy support and ego-involved climate. This amplifies the results of studies that reported the correlation between ego-involved climate and concern over mistakes and the correlation between perceived coach pressure and concern over mistakes in the sport context. The positive relation between the coach's autonomy support and perceived coach pressure is an innovative finding in the SDT literature. It is worth pointing out that no other similar study has been published so far. Therefore, this is an innovative work.

Author Contributions: Conceptualization, H.A.P.-E. and M.T.; methodology, J.L. and J.L.N.; formal analysis, J.L. and J.L.N.; investigation, H.A.P.-E., M.T. and R.M.-S.; resources, H.A.P.-E. and J.L.; data curation, V.M.-S.; writing—original draft preparation, H.A.P.-E.; writing—review and editing, J.L., J.L.N. and V.M.-S.; visualization, R.M.-S. and V.M.-S.; supervision, H.A.P.-E.; funding acquisition, H.A.P.-E. and M.T. All authors have read and agreed to the published version of the manuscript.

Funding: This research was funded by Universidad Autónoma de Baja California (UABC) grant number 21st internal call, program number 1149. The APC was funded by 21st internal call of the UABC.

Institutional Review Board Statement: The study was con-ducted according to the guidelines of the Declaration of Helsinki, and approved by the Ethics Committee of Universidad Autónoma de Baja California (Project 1149).

Informed Consent Statement: Informed consent was obtained from all parents of subjects involved in the study.

Data Availability Statement: The data presented in this study are available on request from the corresponding author.

Acknowledgments: The authors thank Icela López Gaspar for her help in the translation and correction of the English version.

Conflicts of Interest: The authors declare no conflict of interest. 


\section{References}

1. Matosic, D.; Ntoumanis, N.; Quested, E. Antecedents of need supportive and controlling interpersonal styles from a selfdetermination theory perspective: A review and implications for sport psychology research. In Sport and Exercise Psychology Research; Raab, M., Wylleman, P., Seiler, R., Elbe, A.M., Hatzigeorgiadis, A., Eds.; Academic Press: Academic, UK, 2016; pp. $145-180$.

2. Ommundsen, Y.; Roberts, G.C.; Lemyre, P.N.; Miller, B.W. Parental and coach support or pressure on psychosocial outcomes of pediatric athletes in soccer. Clin. J. Sport Med. 2006, 16, 522-526. [CrossRef]

3. Barcza-Renner, K.; Eklund, R.C.; Morin, A.J.S.; Habeeb, C.M. Controlling Coaching Behaviors and Athlete Burnout: Investigating the Mediating Roles of Perfectionism and Motivation. J. Sport Exerc. Psychol. 2016, 38, 30-44. [CrossRef] [PubMed]

4. López-Walle, J.; Balaguer, I.; Castillo, I.; Rodríguez, J. Perceived motivational climate, self-determined motivation and self-esteem in young Mexican athletes. Rev. Psicol. Deporte 2011, 20, 209-222.

5. Ames, C. Achievement goals, motivational climate, and motivational processes. In Motivation in Sport and Exercise; Roberts, G.C., Ed.; Human Kinetics: Champaign, IL, USA, 1992; pp. 161-176.

6. Ryan, R.M.; Deci, E.L. Self-determination theory and the facilitation of intrinsic motivation, social development, and well-being Am. Psychol. 2000, 55, 68-78. [CrossRef] [PubMed]

7. Gutiérrez, M.; Tomás, J.M. Motivational class climate, motivation and academic success in university students. Rev. Psicodidáctica 2018, 23, 94-101. [CrossRef]

8. Deci, E.L.; Ryan, R.M. Self-determination theory. In Handbook of Theories of Social Psychology; Van Lange, P.A.M., Kruglanski, A.W., Higgins, E.T., Eds.; Sage Publications Ltd.: London, UK, 2012; pp. 416-436. [CrossRef]

9. Ryan, R.M.; Deci, E.L. Overview of Self-Determination Theory: An organismic dialectical perspective. In Handbook of SelfDetermination Research; Deci, E.L., Ryan, R.M., Eds.; The University of Rochester Press: Rochester, NY, USA, 2002 ; pp. 3-33.

10. Ryan, R.M.; Deci, E.L. Self-Determination Theory: Basic Psychological Needs in Motivation, Development, and Wellness; Guilford Publications: New York, NY, USA, 2017.

11. Mageau, G.A.; Vallerand, R.J. The coach-athlete relationship: A motivational model. J. Sport Sci. 2003, 21, 883-904. [CrossRef]

12. Ntoumanis, N. A self-determination theory perspective on motivation in sport and physical education: Current trends and possible future research directions. In Motivation in Sport and Exercise; Roberts, G.C., Treasure, S.C., Eds.; Human Kinetics: Champaign, IL, USA, 2012; Volume 3, pp. 91-128.

13. Jang, H.; Reeve, J.; Deci, E.L. Engaging students in learning activities: It is not autonomy support or structure but autonomy support and structure. J. Educ. Psychol. 2010, 102, 588-600. [CrossRef]

14. Flett, G.L.; Hewitt, P.L. Positive versus negative perfectionism in psychopathology: A comment on Slade and Owens's dual process model. Behav. Modif. 2006, 30, 472-495. [CrossRef]

15. Hewitt, P.L.; Flett, G.L.; Mikail, S.F. Perfectionism: A Relational Approach to Conceptualization, Assessment, and Treatment; Guilford Press: London, UK, 2017.

16. Hewitt, P.L.; Flett, G.L. Perfectionism in the self and social context: Conceptualization, assessment and association with psychopathology. J. Personal. Soc. Psychol. 1991, 60, 456-470. [CrossRef]

17. Hewitt, P.L.; Flett, G.L. Perfectionism and depression: A multidimensional analysis. J. Soc. Behav. Personal. $1990,5,423$.

18. Frost, R.O.; Marten, P.; Lahart, C.; Rosenblate, R. The dimensions of perfectionism. Cogn. Ther. Res. 1990, 14, 449-468. [CrossRef]

19. Dunkley, D.M.; Blankstein, K.R. Self-critical perfectionism, coping, hassles, and current distress: A structural equation modeling approach. Cogn. Ther. Res. 2000, 24,713-730. [CrossRef]

20. Stoeber, J. Perfectionism and performance. In Oxford Handbook of Sport and performance Psychology; Murphy, S.M., Ed.; Oxford University Press: New York, NY, USA, 2012; pp. 294-306.

21. Stoeber, J.; Otto, K. Positive conceptions of perfectionism: Approaches, evidence, challenges. Personal. Soc. Psychol. Rev. 2006, 10, 295-319. [CrossRef] [PubMed]

22. Gucciardi, D.F.; Mahoney, J.; Jalleh, G.; Donovan, R.J.; Parkes, J. Perfectionistic profiles among elite athletes and differences in their motivational orientations. J. Sport Exerc. Psychol. 2012, 34, 159-183. [CrossRef] [PubMed]

23. Gotwals, J.K.; Dunn, J.G. A multi-method multi-analytic approach to establishing internal construct validity evidence: The Sport Multidimensional Perfectionism Scale 2. Meas. Phys. Educ. Exerc. Sci. 2009, 13, 71-92. [CrossRef]

24. Hall, H.K.; Kerr, A.W.; Matthews, J. Precompetitive anxiety in sport: The contribution of achievement goals and perfectionism. J. Sport Exerc. Psychol. 1998, 20, 194-217. [CrossRef]

25. Ablard, K.E.; Parker, W.D. Parents' achievement goals and perfectionism in their academically talented children. J. Youth Adolesc. 1997, 26, 651-667. [CrossRef]

26. Carpenter, P.J.; Morgan, K. Motivational climate, personal goal perspectives, and cognitive and affective responses in physical education classes. Eur. J. Phys. Educ. 1999, 4, 31-44. [CrossRef]

27. Carr, S.; Wyon, M. The impact of motivational climate on dance students' achievement goals, trait anxiety, and perfectionism. J. Danc. Med. Sci. 2003, 7, 105-114.

28. Nordin-Bates, S.M.; Hill, A.P.; Cumming, J.; Aujla, I.J.; Redding, E. A longitudinal examination of the relationship between perfectionism and motivational climate in dance. J. Sport Exerc. Psychol. 2014, 36, 382-391. [CrossRef]

29. Ommundsen, Y.; Roberts, G.C.; Lemyre, P.-N.; Miller, B.W. Peer relationships in adolescent competitive soccer: Associations to perceived motivational climate, achievement goals and perfectionism. J. Sports Sci. 2005, 23, 977-989. [CrossRef] 
30. Lemyre, P.N.; Hall, H.K.; Roberts, G.C. A social cognitive approach to burnout in elite athletes. Scand. J. Med. Sci. Sports 2008, 18, 221-234. [CrossRef]

31. Nerland, E.; Arve, S. Norwegian football academy players-players self-assessed competence, perfectionism, goal orientations and motivational climate. Sport Mont. 2016, 14, 7-11. [CrossRef]

32. Bae, M.; Yoon, J.; Kang, H.; Kim, T. Influences of perfectionism and motivational climate on attitudes towards doping among Korean national athletes: A cross sectional study. Subst. Abus. Treat. Prev. Policy 2017, 12, 1-8. [CrossRef] [PubMed]

33. Madigan, D.J.; Curran, T.; Stoeber, J.; Hill, A.P.; Smith, M.M.; Passfield, L. Development of perfectionism in junior athletes: A three-sample study of coach and parental pressure. J. Sport Exerc. Psychol. 2019, 41, 167-175. [CrossRef] [PubMed]

34. Curran, T. Parental conditional regard and the development of perfectionism in adolescent athletes: The mediating role of competence contingent self-worth. Sport Exerc. Perform. Psychol. 2018, 7, 284. [CrossRef]

35. Reigal, R.E.; Crespillo, M.; Morillo, J.P.; Hernández Mendo, A. Autonomy support, perceived motivational climate and psychological sports profile in beach handball players. Cuad. Psicol. Deporte 2018, 18, 102-111.

36. Balaguer, I.; Castillo, I.; Duda, J.L.; Tomás, I. Analysis of the psychometric properties of the Spanish version of the Sport Climate Questionnaire. Rev. Psicol. Deporte 2009, 18, 73-83.

37. Pineda-Espejel, H.A.; Arrayales, E.; Castro, S.; Morquecho, A.; Trejo, M.; Fernández, R. Versión en español de la subescala presión del entrenador del MIPS: Propiedades psicométricas. Eur. J. Investig. Health Psychol. Educ. 2018, 8, 119-127. [CrossRef]

38. Pineda-Espejel, H.A.; Morquecho-Sánchez, R.; Gadea-Cavazos, E. Evidence of test-criterion validity in the use of the SportMultidimensional Perfectionism Scale-2. Cuad. Psicol. Deporte 2018, 18, 129-140.

39. Zinbard, R.E.; Revelle, W.; Yovel, I.; Wen, L. Cronbach's $\alpha$, Revelle's $\beta$, McDonald's $\omega H$ : Their relations with each other and two alternative conceptualizations of reliability. Psychometrika 2005, 70, 123-133. [CrossRef]

40. Muthén, L.K.; Muthén, B.O. MPlus: Statistical Analysis with Latent Variables-User's Guide; Muthén \& Muthén: Los Angeles, CA, USA, 2012.

41. Hair, J.; Babin, B.; Anderson, R.; Black, W. Multivariate Data Analysis, 8th ed.; Pearson Educational, Inc.: London, UK, 2019.

42. Marsh, H.W.; Hau, K.T.; Wen, Z. In search of golden rules: Comment on hypothesis-testing approaches to setting cutoff values for fit indexes and dangers in overgeneralizing Hu and Bentler's (1999) findings. Struct. Equ. Model. 2004, 11, 320-341. [CrossRef]

43. Hu, L.T.; Bentler, P.M. Cutoff criteria for fit indexes in covariance structure analysis: Conventional criteria versus new alternatives. Struct. Equ. Model. 1999, 6, 1-55. [CrossRef]

44. Preacher, K.J.; Hayes, A.F. Asymptotic and resampling strategies for assessing and comparing indirect effects in multiple mediator models. Behav. Res. Methods 2008, 40, 879-891. [CrossRef] [PubMed]

45. Hayes, A.F. Introduction to Mediation, Moderation, and Conditional Process Analysis: A Regression-Based Approach; Guilford Press: New York, NY, USA, 2013.

46. Newton, M.; Duda, J.L.; Yin, Z. Examination of the psychometric properties of the Perceived Motivational Climate in Sport Questionnaire-2 in a sample of female athletes. J. Sport Sci. 2000, 18, 275-290. [CrossRef]

47. Roberts, G.C. Motivation in sport and exercise from an achievement goal theory perspective: After 30 years, where are we? In Advances in Motivation in Sport and Exercise; Roberts, G.C., Treasure, D.C., Eds.; Human Kinetics: Champaign, IL, USA, 2012; pp. 35-58.

48. Baumrind, D. Current patterns of parental authority. Dev. Psychol. Monogr. 1971, 4, 1-103. [CrossRef]

49. Rocchi, M.A.; Pelletier, L.G.; Couture, A.L. Determinants of coach motivation and autonomy supportive coaching behaviours. Psychol. Sport Exerc. 2013, 14, 852-859. [CrossRef]

50. Harackiewicz, J.M.; Larson, J.R. Managing motivation: The impact of supervisor feedback on subordinate task interest. J. Personal. Soc. Psychol. 1986, 51, 547-556. [CrossRef]

51. Iachini, A.L. Development and empirical examination of a model of factors influencing coaches provision of autonomy-support. Int. J. Sports Sci. Coach. 2013, 8, 661-675. [CrossRef]

52. Soenens, B.; Sierens, E.; Vansteenkiste, M.; Dochy, F.; Goossens, L. Psychologically controlling teaching: Examining outcomes, antecedents, and mediators. J. Educ. Psychol. 2012, 104, 108-120. [CrossRef]

53. Stebbings, J.; Taylor, I.M.; Spray, C.M.; Ntoumanis, N. Antecedents of perceived coach interpersonal behaviors: The coaching environment and coach psychological well- and ill-being. J. Sport Exerc. Psychol. 2012, 34, 481-502. [CrossRef] [PubMed]

54. Reeve, J. Why teachers adopt a controlling motivating style toward students and how they can become more autonomy supportive. Educ. Psychol. 2009, 737, 159-175. [CrossRef]

55. Grolnick, W.S.; Apostoleris, N.H. What makes parents controlling? In Handbook of Self-Determination Research; Deci, E.L., Ryan, R.M., Eds.; University of Rochester Press: Rochester, NY, USA, 2002; pp. 161-882.

56. Appleton, P.R.; Hall, H.K.; Hill, A.P. Examining the influence of the parent-initiated and coach-created motivational climates upon athletes' perfectionistic cognitions. J. Sports Sci. 2011, 29, 661-671. [CrossRef] [PubMed]

57. Sapieja, K.M.; Dunn, J.G.H.; Holt, N.L. Perfectionism and perceptions of parenting styles in male youth soccer. J. Sport Exerc. Psychol. 2011, 33, 20-39. [CrossRef]

58. Greblo, Z.; Barić, R.; Erpič, S.C. Perfectionistic strivings and perfectionistic concerns in athletes: The role of peer motivational climate. Curr. Psychol. 2016, 35, 370-376. [CrossRef]

59. Mouratidis, A.; Michou, A. Perfectionism, self-determined motivation, and coping among adolescent athletes. Psychol. Sport Exerc. 2011, 12, 355-367. [CrossRef] 